\title{
Preventative Medicine as a Tool to Ensure Health Equity for Disadvantaged Populations: An Interview with Dr. Kevin Pottie
}

\author{
Mohammed K. Rashid, BHSc ${ }^{1}$, Hiba Abdul-Fattah, BHSc, \\ BA.Psy
}

${ }^{1}$ Faculty of Medicine, University of Ottawa

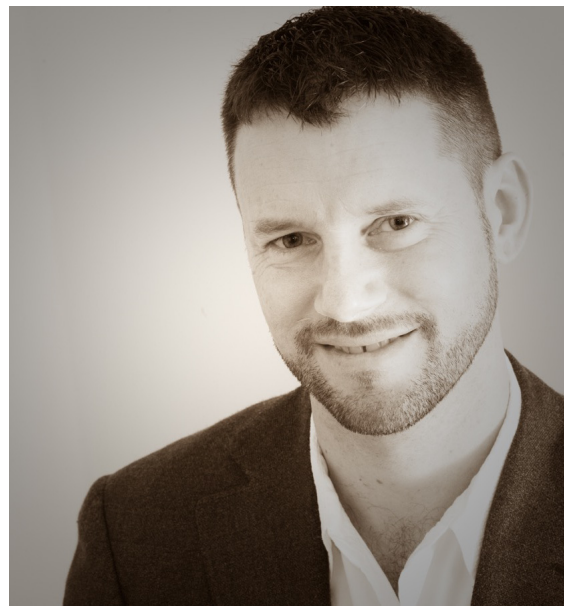

A BSTRACT

"An ounce of prevention is worth a pound of cure." - Benjamin Franklin. In this article, we interview Dr. Kevin Pottie, MD. Dr. Pottie is well known for his clinical and research work on preventative medicine, health equity and evidence-based guidelines, particularly as they relate to disadvantaged populations. We discuss with Dr. Pottie his career as a clinician investigator. He guides us through his journey and shares with us important advice on caring for newly arriving Syrian refugees based on recent published guidelines.

\section{RÉSUMÉ}

« Mieux vaut prévenir que guérir. »-Benjamin Franklin. Dans cet article, nous interviewons Dr Kevin Pottie, MD. Dr Pottie est reconnu pour sa recherche clinique en médecine préventive et en santé équitable particulièrement dans le domaine des populations désavantagées. Dans cette entrevue, Dr Pottie discutera de sa carrière en tant que chercheur clinique et nous partagera des conseils importants sur les soins à donner aux réfugiés syriens nouvellement arrivés au Canada. Ses conseils sont fondés sur des lignes directrices nouvellement publiées.

\section{CAN YOU TELL US ABOUT YOUR EDUCATION, TRAINING, AND CURRENT POSITIONS?}

I completed my undergraduate degree in Psychology, followed by medical school-both at Dalhousie University. I went on to do my training in Family Medicine at the University of Ottawa. Later on, I completed a Master's of Clinical Science in Family Medicine and Refugee Health at Western University.

I am a clinician investigator with a 30:70 division for clinical duties and research. I am an associate professor in the departments of Family Medicine and Epidemiology and Community Medicine at the University of Ottawa, a Principal Scientist at the Bruyère Research Institute, a member of the Canadian Task Force on Preventive Health Care (CTFPHC), and the Chair of the Canadian Collaboration for Immigrant and Refugee Health (CCIRH). The main focus of my research is on developing evidence-based guidelines to improve primary health care for disadvantaged populations.

\section{HOW DID YOU BECOME INTERESTED IN PREVENTATIVE MEDICINE?}

As a young medical student at Dalhousie, I was influenced by one of my mentors, Dr. Joni Guptill. I was completely intrigued by Dr. Guptill's stories from a recent mission with Médecins Sans Frontières (MSF). Soon after, I started to get involved in this field. My first mission with MSF was to address the Abkhazia Region diphtheria epidemic in the Republic of Georgia in 1995. My global health relief work took me to war- and epidemic-inflicted regions all around the world. Currently, the main focus of my work is health equity; of which preventative medicine is a component. Health equity focuses on addressing disparities in health care access and targeting the social determinants of health, such as housing, education, and employment. Preventative medicine and working with disadvantaged populations appealed to me as a medical student because I could appreciate the effect of my work in terms of saving lives and reducing suffering.

Keywords: Preventative medicine; Health equity; Refugee health 


\section{WHAT IS A TYPICAL WEEK LIKE FOR YOU? HOW DO YOU MAINTAIN BALANCE BETWEEN RESEARCH, CLINICAL WORK, AND PERSONAL LIFE?}

As a researcher, I do not really have a typical week. I usually spend three half-days in clinic, which includes teaching family medicine residents and medical students. The rest of my time is devoted to research, which includes conception of projects (usually leading to grants or ethics applications), refining of methods and design, data collection, data analysis and interpretation, and preparation of publications. At any time, I usually have five to ten ongoing research projects plus graduate students' projects. As you advance in your research, you tend to spend most of the research time on conception of projects and data analysis and interpretation and less on data collection, but I continue to do that too. My work necessitates traveling for conferences, as well as team meetings since I collaborate with professionals from all around the world. For instance, I am heading to Saskatoon, Saskatchewan tomorrow to participate in the Refugee Healthcare Conference. The lack of a routine schedule can be challenging at times, but it keeps my job exciting.

Maintaining balance can be rather difficult. My clinical work schedule is usually pre-determined; however, it is research that has no limit and can extend into clinical and even personal life. I have definitely done research work while on vacations, so it is easy to be consumed in your research. However, it is essential to set boundaries and to realize the importance and joy of family and personal life. This in turn will give you energy and motivation to keep going in your clinical and professional endeavours.

\section{CAN YOU TELL US ABOUT ONE OF YOUR INTERESTING PROJECTS?}

In the period between 2005 and 2011, I co-chaired a team to develop the Canadian evidence-based clinical guidelines [1] for immigrants and refugees published in the Canadian Medical Association Journal (CMAJ). This internationally unique set of guidelines for migrant health involved the collaboration of over twenty interdisciplinary teams of clinicians, researchers, and other experts in the field. We subsequently developed a set of preventative checklists for practitioners providing primary care for immigrants and refugees [2]. It allows practitioners the ability to personalize clinical preventative care to patients, based on their region or country of origin and migration history, accounting for factors that impact their health. For example, certain factors such as forced migration, low income and limited proficiency in English and French increase the risk of decline in health and are important factors for consideration in the delivery of preventative care for such populations [2].

\section{YOU HAVE BEEN INVOLVED IN SEVERAL PROJECTS IN PREVENTATIVE MEDICINE FROM THE WORLD HEALTH ORGANIZATION TO THE CTFPHC. WHAT IS YOUR TAKE ON THE CURRENT APPROACH TO PREVENTATIVE MEDICINE?}

Preventative medicine is an exciting area as there continues to be a lot to learn. The government continues to invest in preventative medicine as it realizes the potential for cost savings and improved health outcomes. It is an exciting time to be involved in preventative medicine. For example, the use of genetics and personalized medicine is revolutionizing medicine overall, especially in the case of preventative medicine, as it allows for the identification of risk factors in one's own genome and to tailor preventative measures and interventions accordingly.

The greatest success in preventative medicine, as regarded by many, is the development of vaccinations. However, one of the challenges facing today's preventative medicine (and all areas of medicine for that matter) is access to care; and this is where my interest in health equity fits. I believe that regardless of the advancements we make in medicine, it would not have an impact if we are unable to reach the target populations. Ensuring equitable access to health care services and addressing social determinants of health are important components of the field of preventative medicine.

One mistake we all fall for is the belief that preventative medicine means we need to always do more. The pendulum in preventative medicine seems to have shifted too far towards overscreening, which is a challenge in this field. Overscreening is not without its drawbacks. It can lead to extensive tests, worried patients, and increased costs. It is important that preventative measures are guided by evidence; sometimes it is wiser to not screen. For instance, regular screening for post-traumatic stress disorder (PTSD) among refugees used to be recommended. However, we now know that overscreening for PTSD can re-traumatize vulnerable patients and attach an unnecessary label to them [1]. Our current guidelines advise against routine screening for PTSD, but rather recommend remaining alert [1]. Another example is screening for diabetes. Current guidelines from the Canadian Diabetes Association recommend screening for type 2 diabetes for everyone starting at the age of 40 [3]. However, guidelines from the CTFPHC on screening for type 2 diabetes suggest that there is actually no evidence that this approach reduces the incidence, mortality, or complications of diabetes among adults with low to moderate risk [4]. We were not able to identify randomized trials or observational studies demonstrating that regular screening for type 2 diabetes was associated with improved intermediate (i.e., frequency of diagnosis) or final (i.e., mortality) outcomes among patients with low to moderate risk [4]. All that to say, often it feels advantageous to do more, when it may not be driven by evidence. 


\section{GIVEN THE RECENT ARRIVAL OF SYRIAN REFUGEES IN CANADA, DO YOU HAVE ANY ADVICE FOR CARING FOR THIS PATIENT POPULATION?}

With the recent humanitarian crisis in Syria, Canada was among the leaders in accepting a considerable number of refugees. These refugees arrive with a unique set of emotional, psychological, and physical needs, which present a challenge for primary health care providers. We have recently published a study in the CMAJ with updated recommendations to specifically address this issue [5]. The study discusses the $\mathrm{CCIRH}$ guidelines and the evidence-based preventative checklists as they relate to Syrian refugees, and provides an update of the literature. Feedback from practitioners caring for Syrian refugees from around Canada is helping to inform the guidelines. For example, the guideline recommends screening for hepatitis $C$, since its prevalence is uncertain among Syrian refugees. However, we are learning that hepatitis $C$ is indeed rare among this group.

\section{DO YOU HAVE ANY ADVICE FOR YOUNG LEARNERS WHO ARE INTERESTED IN PREVENTATIVE MEDICINE?}

First, my advice for young learners is to identify an area of interest within preventative medicine (e.g., refugee health, women's health, chronic disease prevention, etc.). I can speak only to preventative medicine as it relates to primary care, but it really applies to all fields of medicine. Second, the role of mentorship is paramount. A mentor can guide the student, create opportunities, and provide connections to important resources. As a mentor, I expect students to have the passion for preventative medicine and to demonstrate continued long-term commitment. Third, I recommend getting involved as early as possible to build knowledge and acquire skills; this can be through research projects, advocacy groups, or international placements. Finally, each person needs to set priorities; for me, my biggest project is the one at home, with my children.

\section{ACKNOWLEDGEMENT}

The authors would like to thank Dr. Kevin Pottie for taking the time to share his knowledge and experiences. The interview has been edited.

\section{REFERENCES}

1. Pottie K, Greenaway C, Feightner J, et al. Overview: evidence-based clinical guidelines for immigrants and refugees. CMAJ. 2011;183(12):E824-E830.

2. Pottie K, Warmington R, Miller K, Raza D. Evidence-Based Preventative Care Checklist for New Immigrants and Refugees [Internet]. Ottawa (ON): Canadian Collaboration for Immigrant and Refugee Health; 2012 [cited 2016 Mar 06]. Available from: http://www.ccirhken.ca/ccirh/checklist_website/index. html.

3. Canadian Diabetes Association Clinical Practice Guidelines Expert Committee. Canadian Diabetes Association 2013 Clinical Practice Guidelines for the Prevention and Management of Diabetes in Canada [Internet]. Can J Diabetes; 2013 [cited 2016 Mar 06]. Available from: http://guidelines.diabetes. ca/fullguidelines.

4. Pottie K, Jaramillo A, Lewin G, et al. Recommendations on screening for type 2 diabetes in adults. CMAJ. 2012;184(15):1687-1696.

5. Pottie K, Greenaway C, Hassan G, Hui C, Kirmayer LJ. Caring for a newly arrived Syrian refugee family. CMAJ. 2016;188(3):207-211. 